might possibly account for the refractive difference. A good photograph taken in 1940 shows the right eye then to be larger in appearance.

There has at various times been much controversy whether megalocornea is an entity or an arrested hydrophthalmia. The work of Kayser, Seefelder, Kestenbaum, Grönholm, Friede, quoted by Anderson ${ }^{1}$, indicates that megalocornea as a definite entity does exist and pedigrees have been published. On the other hand Axenfeld, Fuchs, von Hippel, Treacher Collins and others, thought that the two conditions were different manifestations of the same disease. Zorab ${ }^{2}$ describes a case of megalocornea affecting one eye and hydrophthalmia the other. His description is insufficient, but I feel that the megalocornea was also an arrested hydrophthalmia.

The possibility of Dvr. H. being a megalocornea with juvenile glaucoma affecting the right eye is most unlikely. The lack of symmetry, the wide limbus, the thin sclera, and definite glaucoma, right, all support the contention that this is a case of hydrophthalmia, although the freedom of the corneae from the typical splits of Descemet and opacities is unexpected.

\title{
Summary and Conclusion
}

$A$ case is described with many features which might have suggested diagnosis of megalocornea, but has declared itself as hydrophthalmia. It indicates that the diagnosis of the former condition in the absence of a familial history can be most difflcult and should then be made reservedly.

\section{REFERENCES}

1. ANDERSON, J. RINGLAND- "Hydrophthalmia or Congenital Glaucoma," 1939 .

2. ZoraB, A.-Trans. Ophthal. Soc. U.K., Vol. XI, p. 139, 1930.

\section{AN ELECTROLYSIS APPARATUS DEVISED FOR RETINAL DETACHMENTS*}

BY

\section{G. GORDON-NAPIER \\ NOTTINGHAM}

ELECTROLYSIS was originally used by Schoeler (1893) and Abadie (1893) in the treatment of detachment of the retina but without any success chiefly because they did not search for, find and seal the retinal tear. v. Szily and Machemer in 1934 used bipolar electrolysis with success. Imre used the anodal in 1932 and Vogt the cathodal current in 1934.

- Paper read before the Midland Ophthalmological Society at Nottingham on Tuesday, March 26, 1946. 
Electrolysis is a delicate and non-traumatic method of sealing the retinal tears and the accuracy of the "Strike" can be clearly observed with the ophthalmoscope if the negative electrode is used as the active electrode.

An electrolysis apparatus is usually simple to make and the parts required are generally easy to obtain. The reason for making the apparatus I propose to describe was that none was available in any military hospital in India during my tour of service there. The location of the nearest diathermy apparatus was in a civil hospital more than a hundred miles away. During my three and a half years' service in India this apparatus was used without a milliamperemeter. During my first three months in India I was obliged to send Military patients to this civil hospital to have the diathermy operation for detachment of the retina. Two out of the three cases lost the operated eye. I believe the cause of this catastrophe was severe burning because of no milliamperemeter control.

Before an electrolysis apparatus can be constructed certain essential parts must be purchased and under normal conditions this presents no difficulty. Under service conditions purchasing authority must first be obtained and with a co-operative commanding officer and A.D.M.S. permission to purchase parts up to the value of Rs. 100 was granted. I got into communication with many well known electrical firms with negative results. I then decided I would apply for three days' casual leave and go on a " hunting" expedition. Within twenty-four hours I found the only available milliamperemeter of the moving coil variety made by the General Electric Company-it was an excellent one. The variable resistance was of the carbon type and though I was warned against its use it gave no trouble during three years of use. This together with the terminals were of the type used in wireless sets and were bought from a radio shop. At first we used 360 -volt high tension battery but found this unsatisfactory because of the high humidity during certain times of the year. It was then decided to go on another " hunt" for a rectifier. The recognised firms said that this was not available. I obtained a second hand rectifier in a wireless junk-shop in the Bazaar. The out-put current from this could be varied to $40-60,60-80,80-100,100-120$ volts. $60-80$ volt output was generally used. The circuit of this apparatus is a simple one and is shown in the accompanying diagram (Fig. 1). All the connections were carefully soldered and as a safety measure the apparatus was earthed. The panel for mounting the milliamperemeter, the variable resistance, the on-and-off switch and the positive and negative terminals were of bakelite. The panel fitted into a wooden box about a foot cube. This box also housed the rectifier (Fig. 2). 

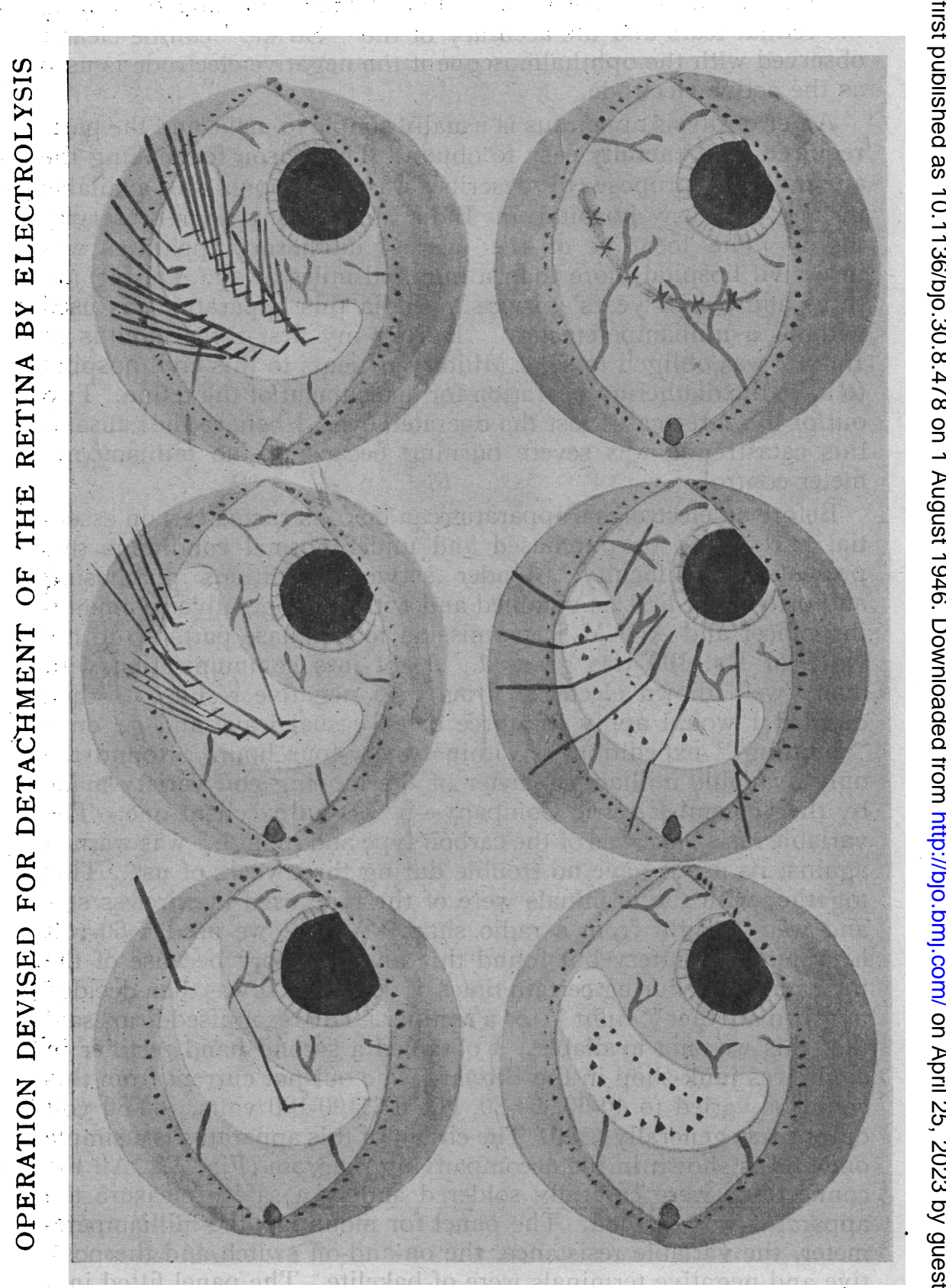

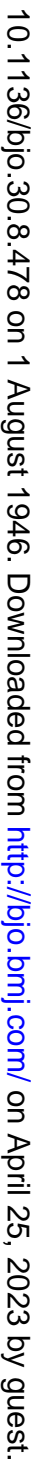




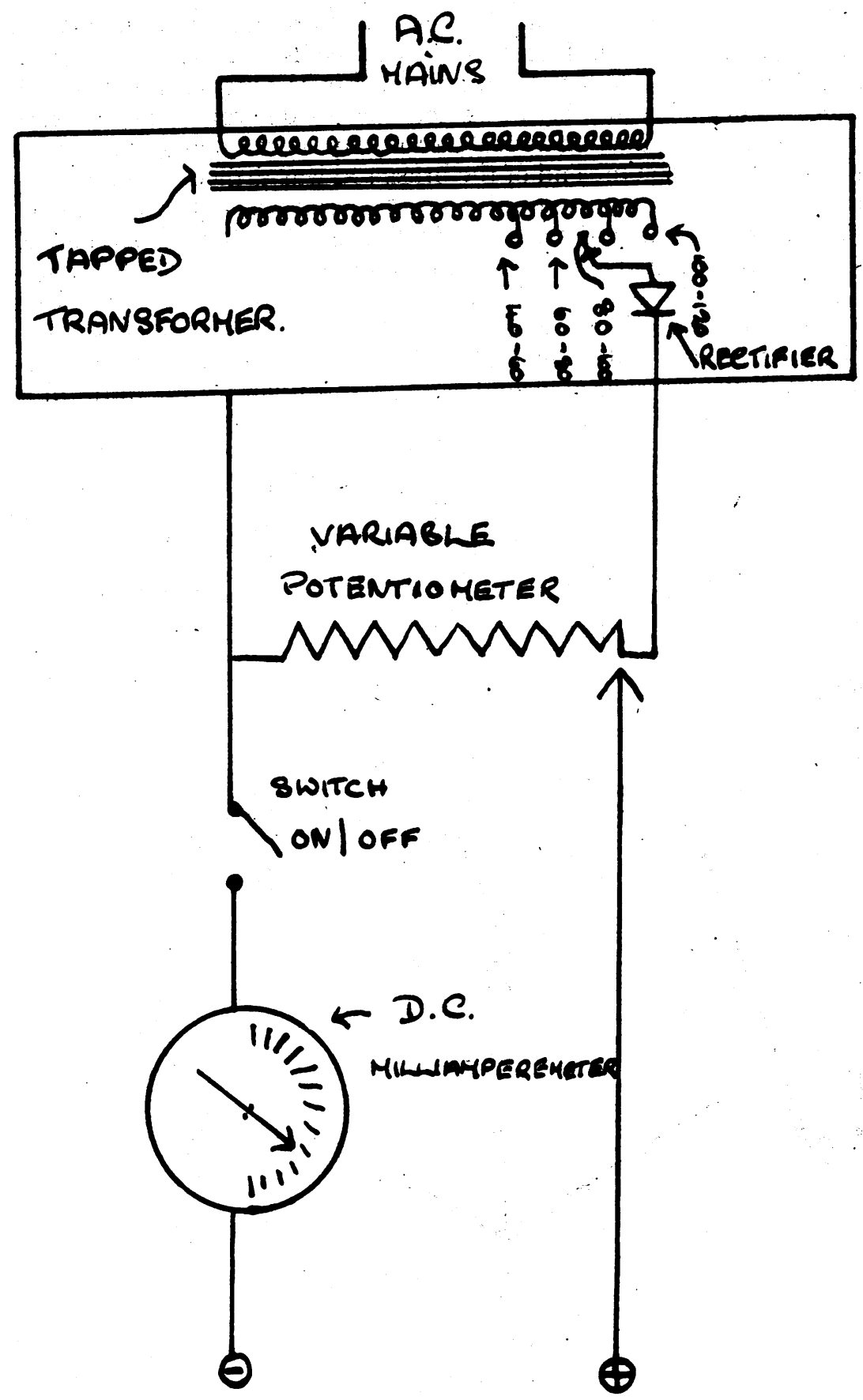

FIG. 1 .

Circuit of electrolysis apparatus devised for detachment of the retina. 
No electrolysis needle-holder could be obtained so we halved an old cautery holder and used this as a needle-holder. In addition to this we made a holder from a fine brass tod insulating this with fibre. The make-and-break switch was made from a small piece of brass ribbon and an ivory button, the latter being part of an ivory ornament. One end of the brass rod was drilled with a watchmaker's drill to take the needle and a thread was cut in the side of the rod to take a mill-screw to fix the needle. The other end of the rod was flanged and threaded to take the flex lead to the apparatus (Fig. 3). The next difficulty was to find fine enough needles. Again the bazaars were searched and the finest needle in stock was No. 20 sewing needle. Several packets of this size were purchased. The needles were first heated with a spirit lamp and blow pipe

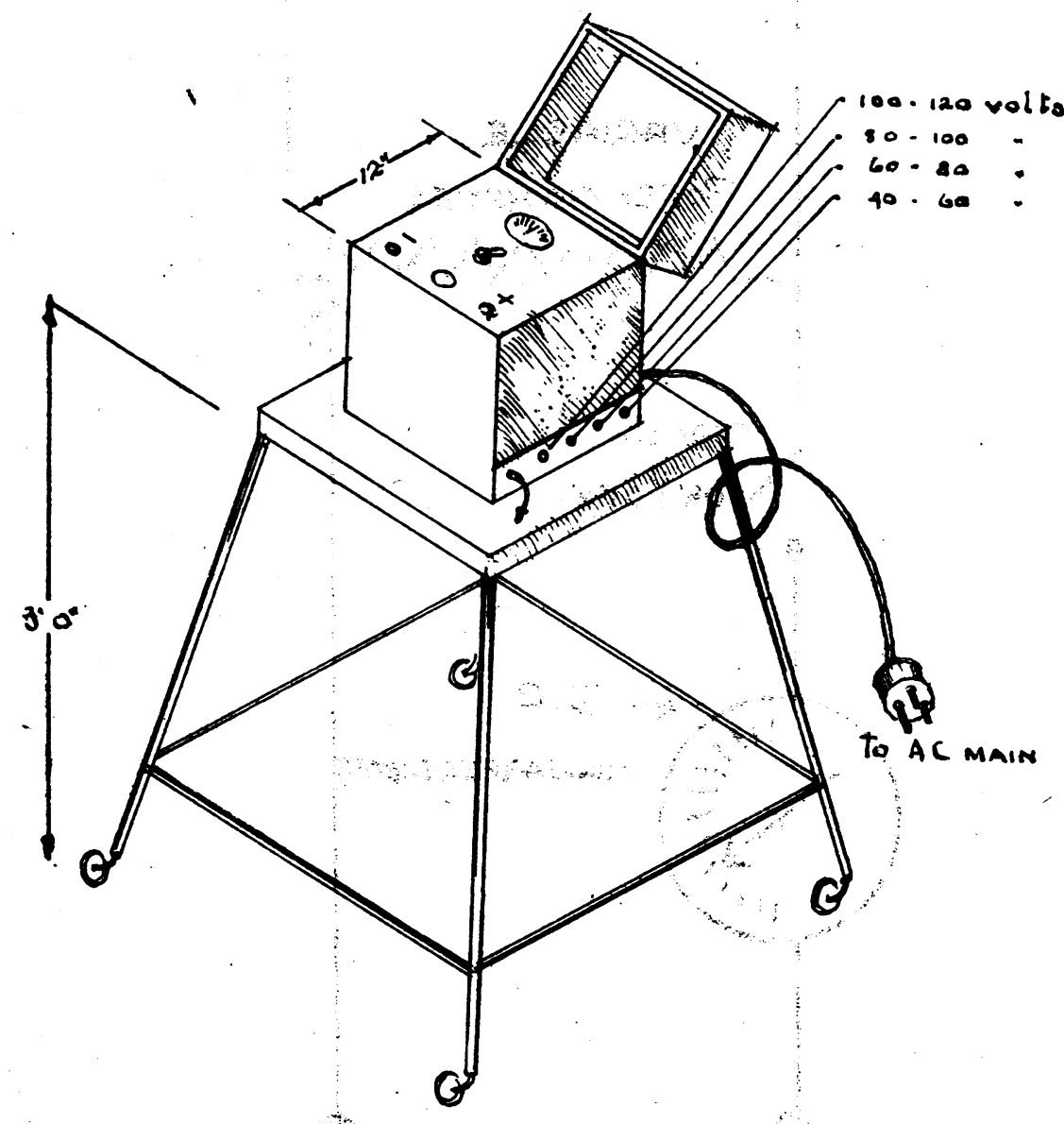

Fig. 2.

Line drawing of box and stand for electrolysis apparatus. 
six millimetres from the pointed end and the needle was bent to 90 degrees so that the applicator end of the needle six millimetres in length was at right angles to the body of the needle. By this method of bending it was found that the needles lost their temper in spite of the fact that they were immersed in oil immediately after bending. This was mentioned to two young, engineers of the R.E.M.E. who immediately: offered us valuable help in the service of a precision instrument maker. This N.C.O. embedded the needles in lead except for a small area $1 \mathrm{~mm}$. in size $6 \mathrm{~mm}$. from the pointed end. Heat was then applied to this small area and the needle bent to a right angle. The needle was immediately plunged into 3 in 1 oil. The temper was retained and the set of 150 needles was used for over three years without any trouble. The indifferent electrode was made from a piece of zinc. The needle

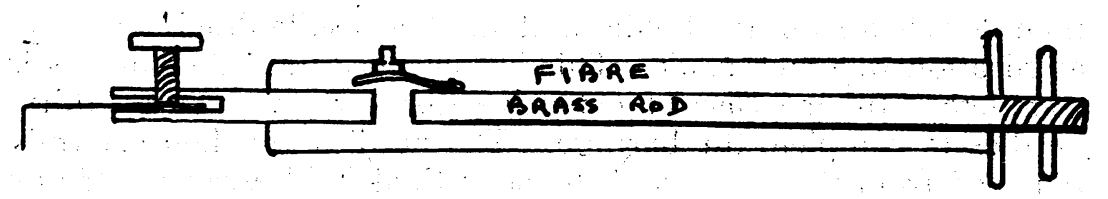

FIG. 3.

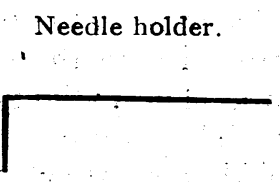

$\mathrm{F}_{1 \mathrm{G}} \cdot 4$

Needle.

fitted into the end of the holder and was held securely in position by a mill screw (Fig. 3:).

In nearly all the cases treated with this "scratch" apparatus the negative pole was used as the active electrode. In every case it was used for localising the Retinal tear. In extensive disinsertions the extreme edge of the rent and the central position of the rent were first localised by means of the negative electrode. The positive electrode was then used to complete the barrage. The fundus was kept under ophthalmoscopic observation throughout the operation. On no occasion was more than $6 \mathrm{~m}$.a. of current used to obtain penetration of the sclera. We found it essential to start the application with full resistance and then gradually lessen the resistance so as to increase the current in a slow steady manner up to the required strength. By strict adherence to this rule much discomfort can be avoided.

In all cases we used careful premedication. One hour before the operation for patients of 9 stone and over morphine hydrochloride 
grs. $\frac{1}{4}$ and hyoscine hydrobromide grs. 1/100th subcutaneously and half an hour before operation 2 grams of penthothal in 20 c.c. of water was given intra-rectally. No instillation anaesthesia was used. With the patient on the operating table $\frac{1}{2}$ c.c. of novutox was injected intra-orbitally through the lower lid. If there was to be any divişion of extra-ocular muscles then a few minims of novutox was injected into the appropriate muscle.

The indifferent electrode was covered with several layers of wet lint and was then bandaged on to the upper arm. The usual exposure was made through the conjunctiva. The needle was fitted into the holder and the first application made in the desired position. For penetration the time of application varied depending on the thickness of the sclera.. On no occasion was the time of application more than 7 seconds and the usual time was about 4 seconds. The strength of current varied between 3 and $6 \mathrm{~m}$.a. The needle was then detached from the holder and another needle fitted. Another application was then made. This is continued until the barrage is complete. In one case of extensive disinsertion we used thirty needles to complete the barrage. The needles are then carefully removed from the sclera and the subretinal fluid escapes. If any muscle has been cut it is resutured and the conjunctiva repaired. The position of nursing depends on the position of the retinal tear. If above the patient is nursed with the 'foot of the bed raised and if below he is propped up. The patients were kept in the agreed position for three weeks. They were then allowed to move about in bed for a week. The fifth week they sat in a chair and the sixth week were allowed to move about the ward.

I have records of twenty-five cases undertaken with this apparatus though many more cases were actually treated (see table). The

Results of 25 Cases of Detachment of the Retina Treated by Electrolysis

\begin{tabular}{|c|c|c|c|}
\hline \multirow[t]{2}{*}{$\therefore$} & \multicolumn{2}{|c|}{ Traumatic } & \multirow[b]{2}{*}{ In Myopes } \\
\hline & Disinsertion & Hole at Macula & \\
\hline Re-attached after first operation & 7 & 1 & 5 \\
\hline $\begin{array}{l}\text { Re-attached after second opera- } \\
\text { tion } \quad \ldots \quad \text {. }\end{array}$ & $\because 3$ & 一 & 1 \\
\hline Failures: & 4 & 1 & 3 \\
\hline
\end{tabular}


most interesting case was that of an infantryman who sustained an injury through a missile being hurled through the barrack room window while he was peacefully reading a book. The stone struck his eye through the closed lids. His vision was immediately blurred and he reported to my Ophthalmic Centre immediately. Examination showed perception of light with a traumatic hole at the macula and an extensive central detachment of the retina. It was impossible to chart the field of vision. He was confined to bed for a week and then operation was performed. The lateral rectus was divided and all subsidiary attachments were carefully cut and the eye pulled medially. We thought the chances of striking the macula were remote. We used a bone shoe horn as an insulator cutting this down to a suitable size. The ordinary needles we had made were unsuitable so we made an applicator of aluminium and soldered five millimetres of No. 20 sewing needle into it. The applicator was curved so as to pass around the globe and was insulated with cellulose paint. The needle was passed around to the posterior pole of the eye and pressure brought to bear. The current used was $4 \mathrm{~m}$.a. for four seconds. On ophthalmoscopic examination bubbles could be seen emerging from the macular hole. The patient was nursed with the foot of the bed on blocks. The sixth week after the operation the field was charted and found to be full to white $2 / 330$ with a small steep-edged central scotoma for white $2 / 1000$ and white $20 / 1000$. There was no detachment. He was re-examined in a year when the field was the same and there was no detachment of the retina. This case was seen before and after operation by Colonel Verdon, Consultant Ophthalmologist to Southern Army, India and Colonel Martin Cruikshank, Consultant Surgeon to Southern Army, India. The latter also has a wide experience in ophthalmology. Twelve cases re-attached after the first operation and were still attached 6 months after operation. Of the remaining twelve cases four re-attached after a second operation performed three to four months after the first. Eight cases were complete failures. One of these had a central detachment with a traumatic hole at the macula. He was an excellent patient and deserved a better result. Of the remaining seven failures three cases were idiopathic detachments in myopes and four were traumatic. Of the twelve successful cases after the first operation seven were traumatic with fairly large disinsertions and five were in myopes with one or more retinal tears. Of the four cases which re-attached after a second operation three were traumatic and one a detachment in a myope. 